\title{
Case Study: Finite Element Method and Artificial Neural Network Models for Flow through Jeziorsko Earthfill Dam in Poland
}

\author{
Gokmen Tayfur ${ }^{1}$; Dorota Swiatek ${ }^{2}$; Andrew Wita ${ }^{3}$; and Vijay P. Singh, F.ASCE ${ }^{4}$
}

\begin{abstract}
A finite element method (FEM) and an artificial neural network (ANN) model were developed to simulate flow through Jeziorsko earthfill dam in Poland. The developed FEM is capable of simulating two-dimensional unsteady and nonuniform flow through a nonhomogenous and anisotropic saturated and unsaturated porous body of an earthfill dam. For Jeziorsko dam, the FEM model had 5,497 triangular elements and 3,010 nodes, with the FEM network being made denser in the dam body and in the neighborhood of the drainage ditches. The ANN model developed for Jeziorsko dam was a feedforward three layer network employing the sigmoid function as an activator and the back-propagation algorithm for the network learning. The water levels on the upstream and downstream sides of the dam were input variables and the water levels in the piezometers were the target outputs in the ANN model. The two models were calibrated and verified using the piezometer data collected on a section of the Jeziorsko dam. The water levels computed by the models satisfactorily compared with those measured by the piezometers. The model results also revealed that the ANN model performed as good as and in some cases better than the FEM model. This case study offers insight into the adequacy of ANN as well as its competitiveness against FEM for predicting seepage through an earthfill dam body.
\end{abstract}

DOI: 10.1061/(ASCE)0733-9429(2005)131:6(431)

CE Database subject headings: Seepage; Dams, earth; Poland; Neural networks; Numerical models; Case reports.

\section{Introduction}

Earthfill and rockfill dams are usually designed under steady state seepage. Anomalous seepage may pose a threat to the integrity of the dam, and any excessive and unplanned seepage may lead to the dam failure. Prediction of infiltration and seepage in time and space and the consequent seepage path through the dam is important for planning and implementing technically and economically sound remedial stability measures.

Seepage paths have been predicted by both physical and mathematical models. Panthulu et al. (2001) used an electrical resistivity method to delineate zones favorable to seepage and a selfpotential method to delineate seepage paths for two of the Saddle dams of the Som-Kamla-Amba project in Rajasthan, India. Turk-

\footnotetext{
${ }^{1}$ Professor, Dept. of Civil Engineering, Faculty of Engineering, Izmir Institute of Technology, Gulbahcekoyu, Urla, Izmir 35347, Turkey. E-mail: gokmentayfur@iyte.edu.tr

${ }^{2}$ Assistant Professor, Dept. of Hydraulic Engineering and Environmental Recultivation, Warsaw Agricultural Univ., Warsaw, Poland. E-mail: dorotams@levis.sggw.waw.pl

${ }^{3}$ Assistant Professor, Institute of Meteorology and Water Management, Dams Monitoring Centre, Warsaw, Poland. E-mail: aw@otkz.pol.pl

${ }^{4}$ A. K. Barton Professor, Dept. of Civil and Environmental Engineering, Louisiana State Univ., Baton Rouge, LA 70803-6405 (corresponding author). E-mail: cesing@1su.edu

Note. Discussion open until November 1, 2005. Separate discussions must be submitted for individual papers. To extend the closing date by one month, a written request must be filed with the ASCE Managing Editor. The manuscript for this paper was submitted for review and possible publication on June 2, 2003; approved on November 16, 2004. This paper is part of the Journal of Hydraulic Engineering, Vol. 131, No. 6, June 1, 2005. @ASCE, ISSN 0733-9429/2005/6-431-440/\$25.00.
}

men et al. (2002) drilled boreholes and used dye trace tests to identify the seepage paths in the rock-fill Kalecik dam in Turkey.

Using a finite element method (FEM) based on an invariant mesh technique, Honjo et al. (1995) analyzed seepage through the saturated-unsaturated zone in the Tarbela dam in Pakistan. They analyzed various stages of reservoir filling and depletion and various conditions of sedimentation in the reservoir. Tien-Kuen (1996) investigated the stability of an earth dam under steady state seepage by a FEM. Naouss and Najjar (1996) developed a finite difference method (FDM) to calculate the piezometer head and seepage velocity at all nodal locations within a permeable stratum. Solving the inverse problem with a steady state model of saturated-unsaturated seepage flow in porous media, $\mathrm{Xu}$ et al. (2003) designed a hydraulically optimal earth-dam cross section.

This study developed a numerical model using the FEM for two-dimensional unsteady state seepage through the saturatedunsaturated zone in an earthfill dam. The FEM model can be more effective when data on the spatial variation of the actual model parameters at every element of the numerical mesh is available. However, such extensive data throughout the entire dam body is seldom available, primarily due to time and budgetary constraints. Furthermore, the numerical solution of the highly nonlinear flow equations is prone to problems of instability and lack of convergence. Thus, in this study, an artificial neural network (ANN) model was also developed for predicting seepage in time and space and the locus of the seepage path utilizing only the water level data at the upper and lower pools of a dam.

ANNs have been recently employed for the solution of many hydraulic, hydrologic, and water resources problems ranging from rainfall runoff (Tokar and Johnson 1999; Rajurkar et al. 2002) to sediment transport (Jain 2001; Tayfur 2002; Nagy et al. 2002) to solute transport (Aziz and Wong 1992; Lu et al. 1998). However, for seepage through an earthfill dam they do not seem to have 
been applied. In addition, it is not clear how they would compare with FEM. These issues are addressed in this case study where both the developed models of FEM and ANN were applied to predict seepage through the body of Jeziorsko earthfill dam in Poland. Piezometers placed on the section of Jeziorsko dam for monitoring seepage have been used since 1995 . The model results were compared using the data obtained from these piezometers. The performance of the two models was also quantitatively analyzed and compared.

\section{Seepage Flow Models}

\section{Unsaturated Flow}

A two-dimensional unsteady flow through an earthfill dam can be described by the Richards equation (Neuman 1975) as

$$
\begin{aligned}
\frac{\partial}{\partial x}\left[k_{r}(h) \cdot\left(k_{x x} \frac{\partial h}{\partial x}+k_{x z} \frac{\partial h}{\partial z}+k_{x z}\right)\right] \\
\quad+\frac{\partial}{\partial z}\left[k_{r}(h) \cdot\left(k_{z x} \frac{\partial h}{\partial x}+k_{z z} \frac{\partial h}{\partial z}+k_{z z}\right)\right]+S \\
=\left[C(h)+S_{w} S_{s}\right] \frac{\partial h}{\partial t}
\end{aligned}
$$

where $h=$ soil-water pressure $(h>0$ in the saturated zone; $h<0$ in the unsaturated zone; $h=0$ at the water table); $k_{r}(h)=$ relative hydraulic conductivity expressed as $k_{r}(h)=k(h) / k_{s}$, where $k(h)$ $=$ hydraulic conductivity and $k_{S}=$ saturated hydraulic conductivity $\left[k_{r}(h)=1\right.$ in the saturated zone]; $C(h)=$ differential water capacity characterizing the change in the water retention due to the change in the water content, i.e., $C(h)=d \theta / d h$, where $\theta=$ water content and $C(h)$ is equal to zero in the saturated zone; $S_{w}=$ water saturation ratio which is equal to $\theta / \theta_{s}$, where $\theta_{s}=$ saturated water content and $\theta=\theta_{s}$ in the saturated zone and $S_{w}$ is equal to 1 in the fully saturated zone and it is equal to 0 in the fully unsaturated zone; $S_{S}=$ specific water retention; $S=$ source water discharge, such as seepage from a ditch per unit volume per unit time; and $K=\left[\begin{array}{ll}k_{x x} & k_{x z} \\ k_{x x} & k_{z z}\end{array}\right]=$ two-dimensional tensor of hydraulic conductivity.

Eq. (1) can be employed to simulate two-dimensional unsteady state water flow through a nonhomogeneous, anisotropic, saturated-unsaturated porous media receiving lateral flow, $S$. It is usually assumed that in the unsaturated zone the impact of the consolidation on the water retention is negligible compared to the effect of changes in retention resulting from the change in the water content. Hence it is assumed that $S_{s}=0$ in the unsaturated zone.

The relation between the water content $(\theta)$ and the soil-water pressure $(h)$ can be described using the empirical formula of Van Genuchten (1979)

$$
\frac{\theta-\theta_{r}}{\theta_{s}-\theta_{r}}=\left[\frac{1}{1+(\alpha \cdot|h|)^{n}}\right]^{\beta}
$$

where $\theta_{r}=$ residual water content; $\alpha, n$, and $\beta=$ parameters; and $\beta$ is expressed as $\beta=(1-a / n)$, where $a=$ parameter which can take on a value of 1 (Mualem 1976) or 2 (Burdine 1953). $C(h)$ :

Following Eq. (2), one can find the following expression for

$$
C(h)=\frac{d \theta}{d h}=\frac{(n-1) \cdot \alpha^{n} \cdot\left(\theta_{s}-\theta_{r}\right)}{\left[1+(\alpha \cdot|h|)^{n}\right]^{\beta+1}} \cdot|h|^{n-1}
$$

The hydraulic conductivity $[k(h)]$ is related to the soil-water pressure $(h)$ as (Van Genuchten 1979)

$$
k(h)=k_{s}\left[\frac{1}{1+(\alpha \cdot h)^{n}}\right]^{\beta \cdot a} \cdot\left\{1-\left[\frac{(\alpha \cdot h)^{n}}{1+(\alpha \cdot h)^{n}}\right]^{\beta}\right\}^{p}
$$

where $p=$ parameter which can take on a value of 1 (Burdine 1953) or 2 (Mualem 1976).

The solution of Eq. (1) yields the spatial and temporal distribution of the soil-water pressure field in the domain of interest. Consequently, it is possible to determine the position of the water level corresponding to the zero pressure, i.e., isoline $h=0$, and to find other quantities describing the soil-infiltration and seepage characteristics in the dam, such as the spatial and temporal distribution of the water content and hydraulic head.

\section{Finite Element Model}

Eq. (1) was solved using the finite element method (FEM). Accordingly, Eq. (1) was reduced to the following system of firstorder nonlinear differential equations (Neuman 1975):

$$
A_{i j} h_{j}+F_{i j} \frac{\partial h_{j}}{\partial t}=Q_{i}-B_{i}+D_{i}, \quad i, j=1,2, \ldots, m
$$

where

$$
\begin{gathered}
A_{i j}=\sum_{e}^{L e} \frac{1}{4 \Delta} \bar{k}_{r}\left[k_{x x} b_{i} b_{j}+k_{x z}\left(b_{i} c_{j}+b_{j} c_{i}\right)+k_{z z} c_{i} c_{j}\right], \\
i, j=1,2, \ldots, m \\
F_{i j}=\sum_{e}^{L e} \frac{\Delta}{12}\left[\left(2 C_{i}+C_{j 1}+C_{j 2}\right)+S_{s}\left(2 S_{w i}+S_{w j 1}+S_{w j 2}\right)\right] \\
\text { for } i=j, \quad \text { otherwise } F_{i j}=0 \\
Q_{i}=-\sum_{e}^{L e} \frac{(L q)_{i}}{2} \\
B_{i}=\sum_{e}^{L e} \bar{k}_{r}\left(k_{s z} c_{i}\right) \\
D_{r}=\frac{1}{3}\left(k_{r i}+k_{r j 1}+k_{r j 2}\right) \\
\sum_{e}^{L e} \frac{\Delta}{3} \cdot S_{i} \\
D_{i}
\end{gathered}
$$

where $(L q)_{i}$ depicts the flow at the boundary of the length $L$ at element $(e)$, where the Neumann boundary condition is posed; $j_{1}$, $j_{2}=$ number of the remaining nodes in the element; $m=$ number of nodes; $L e=$ number of elements; $\Delta=$ area of the triangular element $(i, j, k) ; a_{i}=x_{j} z_{k}-x_{k} z_{j}$, where $i=1,2,3 ; j=2,3,1 ; k=3,1,2 ; b_{i}$ $=z_{j}-z_{k}$; and $c_{i}=x_{k}-x_{j}$. Note that $D_{i} \neq 0$ for nodes where the source function $S \neq 0$ is determined.

The time derivative in Eq. (5) was approximated by the backward difference method. The predictor-corrector and Picard's iteration methods were employed for the solution of the resulting system of algebraic nonlinear equations. The predictor-corrector method linearizes the system of equations at each time step and 


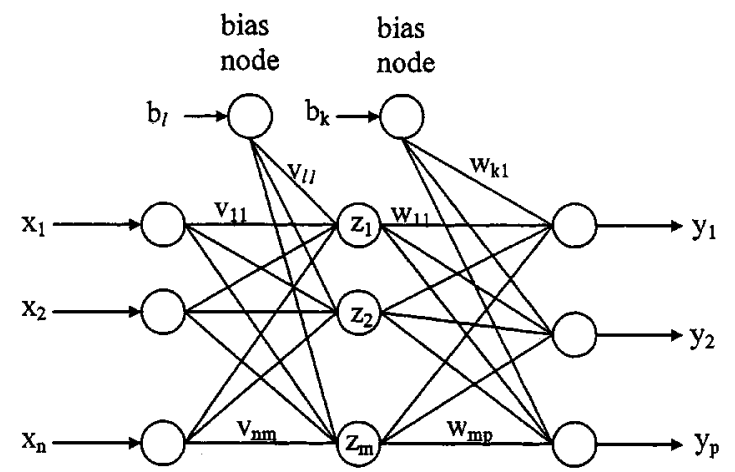

$\begin{array}{lllll}\text { input } & \text { input } & \text { hidden } & \text { output } & \text { output } \\ \text { vector } & \text { layer } & \text { laver } & \text { layer } & \text { vector }\end{array}$

Fig. 1. Representation of three layer feed-forward artificial neural networks

Picard's method iteratively solves the resulting system, which has a large and sparse coefficient matrix, utilizing the method of successive overrelaxation (SOR).

The right choice of the time step $(\Delta t)$ is essential in order to have a stable numerical scheme. The right time step, taking into account the change in the water content in the flow region, was selected following Belmans et al. (1983) as

$$
\Delta t \leqslant \frac{\Delta \theta_{\max }}{\left(\frac{\Delta \theta}{\Delta t}\right)_{\max }}
$$

where $\Delta \theta_{\max }=$ maximum incremental increase in the water content $\theta$. The value selected from the range of $0.001<\Delta \theta_{\max }$ $<0.002$ resulted in stable numerical solutions.

The value of $C(h)$ determined from Eq. (3) leads to large errors in the numerical model (Celia et al. 1990; Ross 1990; Paniconi et al. 1991; Li 1993; Rathfelder and Abriola 1994; and Tocci et al. 1997). Therefore $C(h)$ was evaluated effectively by following Cooley (1983) and Abriola and Rathfelder (1993) as

$$
C_{i}=\frac{D_{t} \theta_{i}^{m}}{D_{t} h_{i}^{m}}=\frac{\theta_{i}^{m}-\theta_{i, t}}{h_{i}^{m}-h_{i, t}}, \quad h_{i}^{m} \neq h_{i, t}
$$

where

$$
\begin{aligned}
& D_{t} \theta_{i}^{m} \equiv \frac{\theta_{i}^{m}-\theta_{i, t}}{\Delta t} \\
& D_{t} h_{i}^{m} \equiv \frac{h_{i}^{m}-h_{i, t}}{\Delta t}
\end{aligned}
$$

Note that when $h_{i}^{m} \approx h_{i, t}$, then $C_{i}$ is evaluated from Eq. (3).

\section{Artificial Neural Networks}

ANNs have an ability to identify relationships from given patterns and hence they have an ability to solve large-scale complex problems, such as pattern recognition, nonlinear modeling, classification, association, and control. Their hydraulic applications generally consider a three-layer feedforward artificial neural network, as shown in Fig. 1. In a feedforward ANN, the input quantities $\left(x_{i}\right)$ are fed into the input layer neurons which, in turn, pass them on to the hidden layer neurons $\left(z_{i}\right)$ after multiplication by connection weights $\left(v_{i j}\right)$ (Fig. 1)

$$
n e t_{j}=\sum x_{i} v_{i j}-b_{j}
$$

A hidden layer neuron adds up the weighted input received from each input neuron $\left(x_{i} v_{i j}\right)$, associates it with a bias $\left(b_{j}\right)$, and then passes the result $\left(n e t_{j}\right)$ on through a generally employed nonlinear sigmoid transfer function

$$
f\left(n e t_{j}\right)=\frac{1}{1+e^{-n e t_{j}}}
$$

The learning of ANNs is generally accomplished by the most commonly used supervised training algorithm of the backpropagation algorithm. The objective of the back-propagation algorithm is to find the optimal weights that would generate an output vector $\boldsymbol{Y}=\left(y_{1}, y_{2}, \ldots, y_{p}\right)$ as close to the target values of the output vector $\boldsymbol{T}=\left(t_{1}, t_{2}, \ldots, t_{p}\right)$ as possible with the selected accuracy. The optimal weights are found by minimizing a predetermined error function $(E)$ of the following form (ASCE Task Committee 2000):

$$
E=\sum_{P} \sum_{p}\left(y_{i}-t_{i}\right)^{2}
$$

where $y_{i}=$ component of an ANN output vector $\boldsymbol{Y} ; t_{i}$ =component of a target output vector $\boldsymbol{T} ; p=$ number of output neurons; and $P=$ number of training patterns.

In the back-propagation algorithm, the effect of the input is first passed forward through the network to reach the output layer. After the error is computed, it is then propagated back towards the input layer with the weights being modified. The gradientdescent method, along with the chain rule of differentiation, was employed to modify the network weights as (ASCE Task Committee 2000)

$$
\Delta v_{i j}(n)=-\delta \frac{\partial E}{\partial v_{i j}}+\alpha_{m} \Delta v_{i j}(n-1)
$$

where $\Delta v_{i j}(n)$ and $\Delta v_{i j}(n-1)=$ weight increments between node $i$ and $j$ during the $n$th and $(n-1)$ th pass or epoch; $\delta=$ learning rate; and $\alpha_{m}=$ momentum factor.

An equation similar to Eq. (19) was also used to correct the bias values. The learning rate $(\delta)$ was used to increase the likelihood of avoiding the training process being trapped in a local minimum instead of a global minimum. However, it is possible that the training process can still be trapped in a local minimum despite the use of a learning rate. The solution often follows a zigzag path while trying to reach a minimum error and this may slow down the training process. The momentum factor $\left(\alpha_{m}\right)$ can be employed to speed up training in very flat regions of the error surface and help prevent oscillations in the weights (ASCE Task Committee 2000).

The network learns by adjusting biases and weights that link its neurons. Before training, weights and biases of the network must be set to small random values. Also, due to the nature of the sigmoid function used in the back-propagation algorithm, all external input and output values before passing them into a network should be standardized. Without standardization, large values of input into an ANN would require extremely small weighting factors to be applied and this could cause a number of problems (Dawson and Wilby 1998). Since sigmoid function extends to minus infinity and plus infinity asymptotically, it never reaches zero or one. Therefore in most cases it is better to compress the 


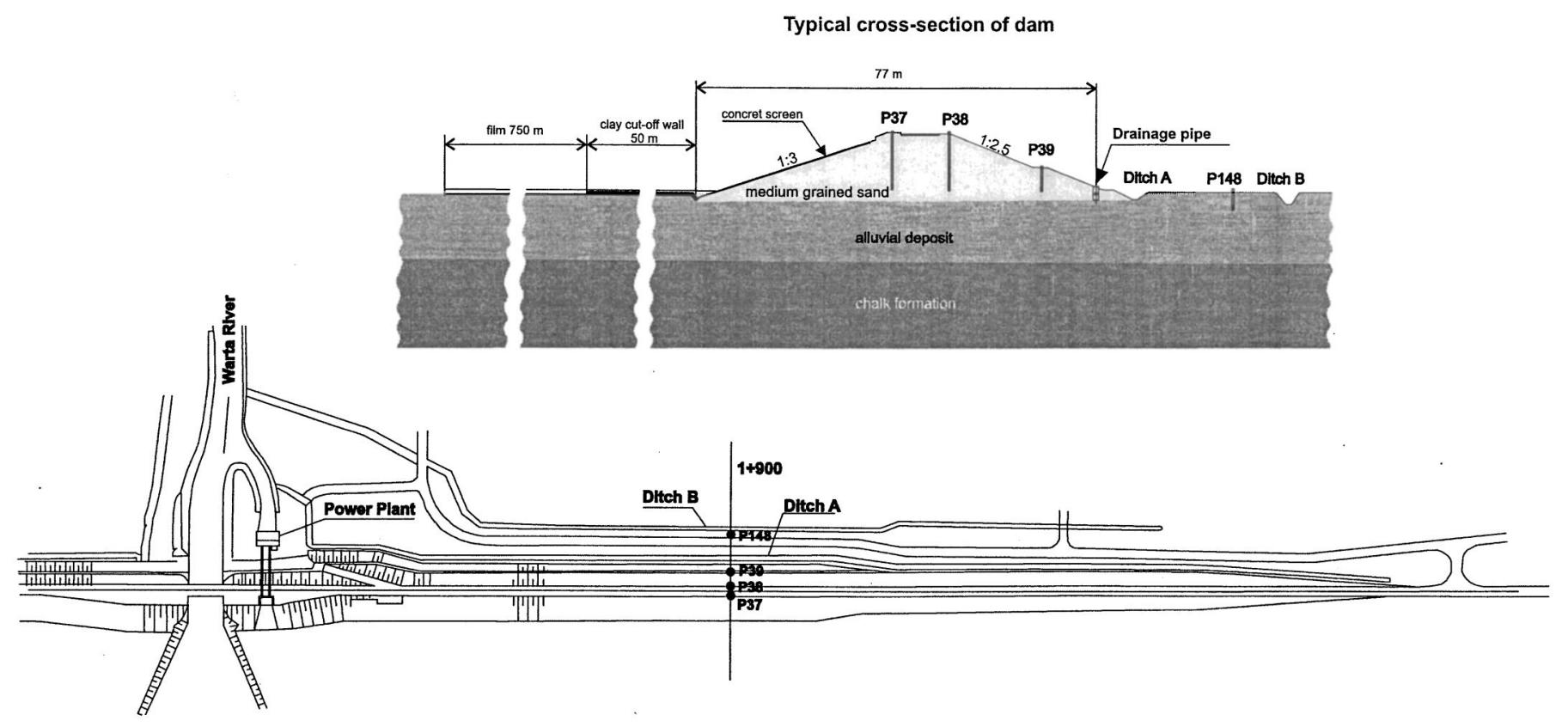

Fig. 2. Detailed cross-section sketch of the Jeziorsko earth-fill dam with depicted soil layers

data into the 0.1-0.9 range. Eq. (20), which compresses all the data into the range of $0.1-0.9$, was employed, in this study, for standardization

$$
x_{i}=0.1+\frac{0.8\left(x_{i}-x_{\min _{i}}\right)}{\left(x_{\max _{i}}-x_{\text {min }_{i}}\right)}
$$

where $x_{\max _{i}}$ and $x_{\min _{i}}$ are the maximum and minimum values of the $i$ th neuron in the input layer for all the feed data vectors, respectively.

\section{Application: A Case Study of Jeziorsko Dam}

The Jeziorsko earthfill dam located in the central part of Poland was employed in this study to calibrate and verify the FEM and ANN models. The dam partitions the Warta River valley near Uniejow City and forms, with other lateral dams, a reservoir area of $42.3 \mathrm{~km}^{2}$. The maximum water rise is $121.5 \mathrm{~m}$ above the mean sea level and its reservoir capacity is 202 million $\mathrm{m}^{3}$. The dam body is homogeneous, constructed with medium grained sand. The length of the dam is $2,720 \mathrm{~m}$ and its height is $12 \mathrm{~m}$. The upstream slope is secured with a tight ferroconcrete screen joined with a clay cutoff wall of $0.5 \mathrm{~m}$ thickness and $50 \mathrm{~m}$ width. A seal made up of a film and extending down to $800 \mathrm{~m}$ inside the reservoir forms an extension of the clay cutoff wall. The cross section $1 \pm 900$ of the Jeziorsko dam was considered for determining infiltration and seepage. Fig. 2 shows a schematic representation of the cross section of the dam. The slope of the upstream side is $1: 3$ while the inclination of the downstream side is 1:2.5. The cross section has two different layers of the geological formation. The lower layer, $35 \mathrm{~m}$ thick, represents an alluvial deposit that overlies a chalk formation and the upper layer represents a quaternary formation (medium grained sand) (Fig. 2). The upper part of the chalk layer is impermeable and therefore the bottom part of the alluvial deposit forms the model boundary. The infiltration model parameters, $\alpha, n, \theta_{r}, \theta_{s}$, and $k_{s}$, for the two layers are given in Table 1. The geological material at the dam toe involves rocky sediments of chalk, clay-dust glacier formations, and sand-gravel alluvial deposits.

On the downstream side of the toe of the dam, at a height of $112.7 \mathrm{~m}$ and at a distance of about $77 \mathrm{~m}$ from the upstream side of the dam, a stoneware drainage of 30 -cm-diameter pipe is installed (Fig. 2). At about every $80 \mathrm{~m}$ there are openings carrying away the water from the drainage pipe down to the drainage ditch (Ditch A in Fig. 2) situated at about a height of $112.3 \mathrm{~m}$ and a distance of $5 \mathrm{~m}$ from the drainage pipe (Fig. 2). The second drainage ditch (Ditch B in Fig. 2) runs parallel to the first (Ditch A) at a height of $112 \mathrm{~m}$ and a distance of about $35 \mathrm{~m}$ from Ditch A. The bottom and the slopes of the ditches are secured with ferroconcrete panels separated by openwork panels.

The infiltrated water flows in the direction from the upstream side towards the downstream side. What affects the infiltration and seepage is the pressure gradient due to the difference in the water levels in the upstream and downstream sides of the dam,

Table 1. Hydraulic Parameters of the Soil Layers

\begin{tabular}{|c|c|c|c|c|c|}
\hline Layer type & $\alpha$ & $n$ & $\begin{array}{c}\theta_{r} \\
{\left[\mathrm{~cm}^{3} / \mathrm{cm}^{3}\right]}\end{array}$ & $\begin{array}{c}k_{s} \\
{[\mathrm{~cm} / \text { day }]}\end{array}$ & $\begin{array}{c}\theta_{s} \\
{\left[\mathrm{~cm}^{3} / \mathrm{cm}^{3}\right]}\end{array}$ \\
\hline $\begin{array}{l}\text { Upper } \\
\text { (medium grain sand) }\end{array}$ & 0.02307 & 1.46826 & 0.0012 & 172.8 & 0.364 \\
\hline $\begin{array}{l}\text { Lower } \\
\text { (alluvial deposit) }\end{array}$ & 0.17327 & 1.82043 & 0.003 & 1728 & 0.395 \\
\hline
\end{tabular}




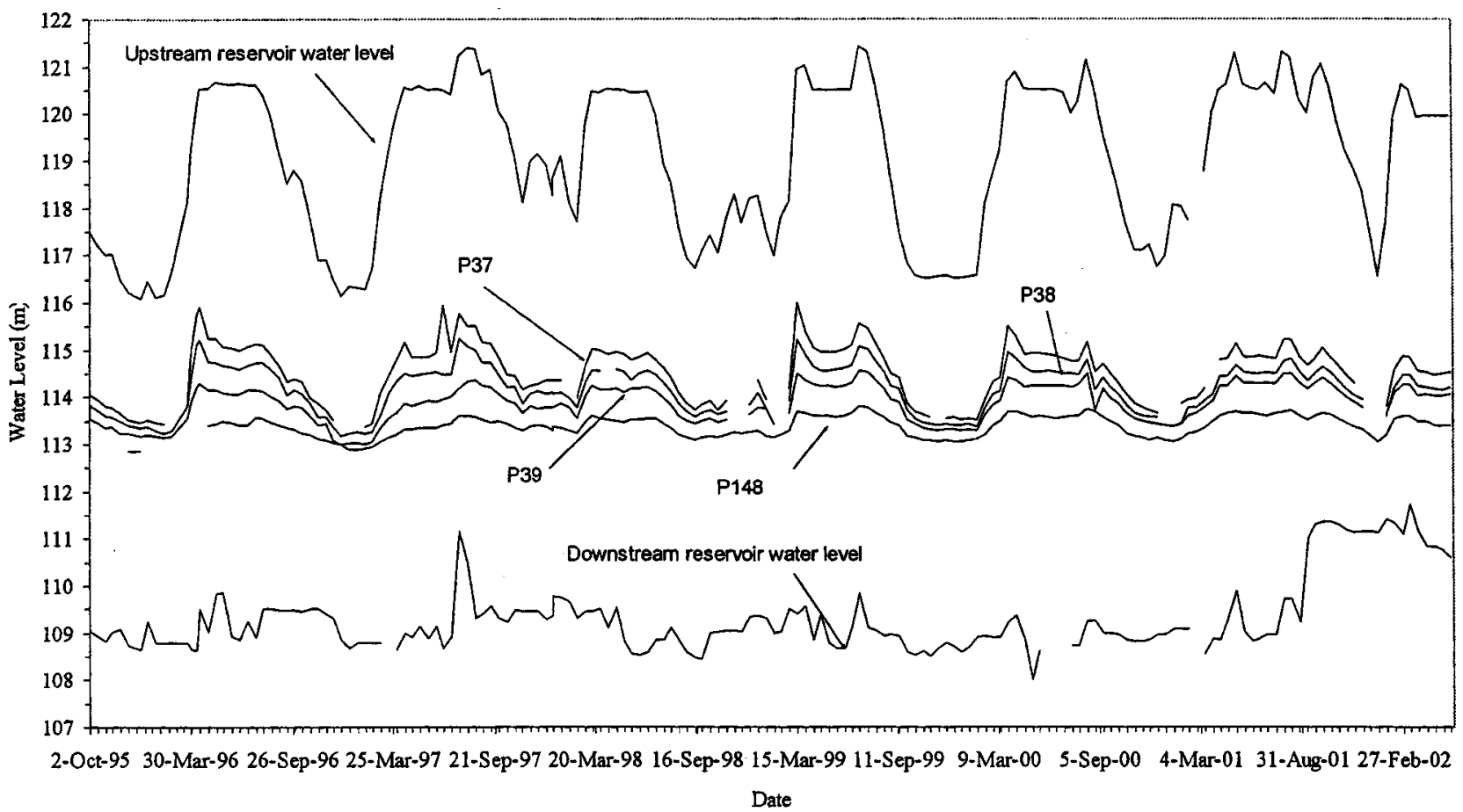

Fig. 3. Temporal variations of water level in piezometers and in the upper and lower reservoirs

tubular drainage, and two drainage ditches. Four piezometers were placed in the dam in order to monitor the flow of infiltrated water through the dam body (Fig. 2). Three piezometers (labeled as P37, P38, and P39) were placed on the dam body whereas one piezometer (labeled as P148) was placed in the alluvial deposit layer (see Fig. 2). The water levels in the piezometers have been measured every 2 weeks since 1995 . Fig. 3 presents the water levels measured in the piezometers and the levels in the upper and lower reservoirs of the dam for the period from October 2, 1995 to May 20, 2002. According to the observed records, the water levels in Ditch A and Ditch B have been constant and are equal to 112.4 and $112.1 \mathrm{~m}$, respectively. There is no data available on the drainage outflow. According to Fig. 3, the water level in P148 is higher than that in Ditch A although P148 is located further down from Ditch A. Ditch A and Ditch B do local draining in the vicinity of their locations, thus lowering only the local head in nearby areas. On the other hand, the actual total head pressure is transferred from the upstream side of the dam through the basement of the dam body to alluvial deposit where P148 is located resulting in the head in P148 to be higher than that in Ditch A.

It has been observed that the horizontal screen sealing the upstream and downstream slopes of the dam have a significant impact on the water level. The technical state evaluation of the dam shows that the horizontal screen is tight and there is leakage on the upstream slope.

\section{Initial and Boundary Conditions}

A numerical solution of Eq. (1) requires the specification of appropriate initial and boundary conditions. Initially the soil-water pressure field needs to be specified. For the boundary conditions, as appropriate, the Neumann-, Dirichlet- and/or Cauchy-type conditions can be specified. For the FEM solution the initial soilwater pressure was specified as the initial condition. It was assumed that the horizontal screen was completely tight and the Neumann boundary condition of zero water flux was employed for this segment of the boundary. At the untight screen on the upstream side it was assumed that the leakage was uniformly distributed and the Cauchy boundary condition of nonzero water flux was employed for this segment of the boundary. The Cauchy boundary condition assumes that the difference between the known total pressure head $\left(H_{a}\right)$ and the unknown pressure head in the region of the interest $(H)$ was caused by the water flux $q$ as

$$
q(x, z, t)=\frac{H_{a}(x, z, t)-H(x, z, t)}{\gamma}
$$

where $\gamma$ represents the resistance to the input to/output from the region.

The Dirichlet boundary conditions in terms of the water level on the upstream and downstream sides of the reservoir were expressed at the left and right parts of the analyzed cross section. The Neumann boundary condition, $q_{0}=0$, was specified for the nodes at the border of the upstream slope above the upper water. In the drainage ditches, the Dirichlet boundary condition was employed as $H_{0}(t)=z+h_{0}(t)=112.4$ and $112.1 \mathrm{~m}$ for Ditches A and $B$, respectively. The impermeable boundary of the lower layer was described by the Neumann boundary condition, i.e., $q=0.0$ (upper part of chalk layer-Fig. 2).

It was assumed that on the downstream slope and farther on the terrain surfaces in the direction of lower water level, there might be free water outflow described by the so-called potential boundary condition. In mathematical formulations, this type of boundary condition reduces to the Dirichlet type as $h=0$ for the saturated zone or the Neumann type as $q=0$ for the unsaturated zone. The numerical model changes the condition type automatically at any instant of time, depending upon the calculated value of the flow flux $(q)$ and/or the soil-water pressure $(h)$.

The interaction between the drainage and the surroundings takes place on the boundaries. The effect of the drainage may be described as a point source (de Marsily 1986; and Fipps and Skaggs 1986) or as a boundary condition. The type of the bound- 

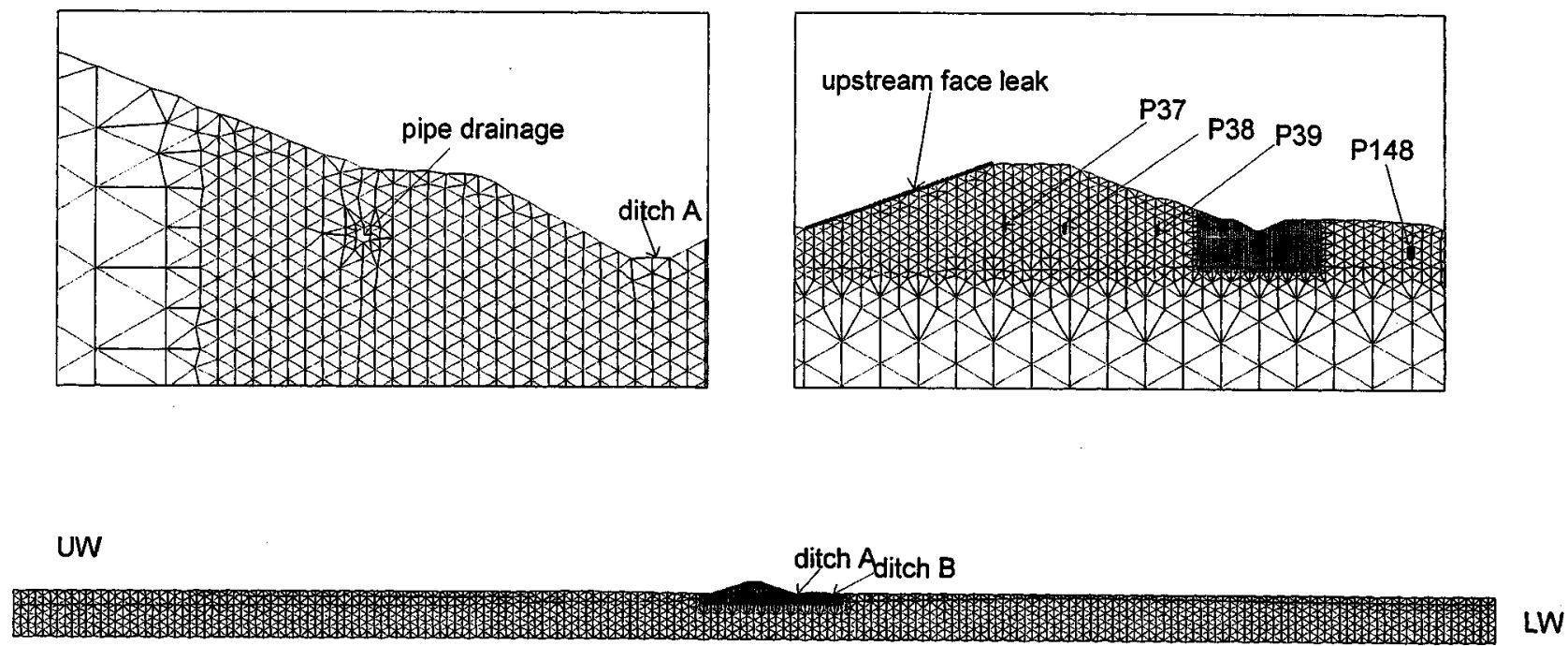

Fig. 4. Layout of the computational network, antifiltration protections and piezometers locations

ary condition on the drainage depends on the available information. In this study, the effect of drainage was reflected as a potential boundary condition of free outflow. Depending upon the pressure distribution in the region, the drainage boundary was located either in the saturated or unsaturated zone or in both. Part of the drainage layout in the saturated zone was considered active and the related boundary condition was described as the free outflow boundary condition as $H=h+z=z$, where $h=0$ and $q<0$. This implies that there is a free flow from the dam body through this segment of the boundary. Evidently, it was assumed that the drainage is capable of carrying away all the water flowing through the cross section of the boundary. The remaining drainage points located in the unsaturated zone were considered as not active and they were modeled by the condition: $q=0$ and $h<0$. Depending upon infiltration, the location of the boundary might shift from one region to the other.

\section{Numerical Model Calibration and Verification}

A program, called FILTRANS (Swiatek 2002), was used for the simulation of infiltration, seepage, and seepage path. FILTRANS solves unsteady infiltration through an earthen hydraulic structure of embankment type. The region of interest (the cross section 1 +900 of the Jeziorsko dam) was divided into triangular finite elements, as shown in Fig. 4. The network was composed of 5,497 triangular elements and 3,010 nodal points. The network was made denser in the dam body and in the neighborhood of the drainage ditches (Fig. 4). The elements in the vicinity of the tubular drainage were radially placed in order to be consistent with the flow in this region. The data obtained from piezometers P37, P38, P39, and P148, as shown in Fig. 3, were used for model calibration and verification. The first three piezometers are placed in the dam body and P148 is placed in the upper part of the alluvial deposit layer (Fig. 2). The calibration involved the evaluation of the leakage from the upstream slope and determining the value of the coefficient $\gamma$ in Eq. (21). The pressure field calculated for the steady state was assumed to form the initial condition.

The model was calibrated by comparing the model results with the measured data of 1 year from June 21, 1999 to June 19, 2000. This period, which corresponded to the construction job, contained all the possible variations of water rise in the upper reservoir. Fig. 5 presents the calibration runs comparing the predicted model results with the measured water level values of each piezometer. Fig. 6(a) shows measured water levels versus FEMpredicted water levels presented in Fig. 5. The coefficient of determination $\left(R^{2}\right)$ is 0.97 and the slope of the regression line is almost one and the intercept is close to zero, implying a successful calibration of the FEM model. In order to objectively evaluate the model performance, the most commonly employed error measures, such as the root mean square error (RMSE) and the mean absolute error (MAE) were computed for each case as shown in Fig. 5 and summarized in Table 2. The calibrated value of $\gamma$, which resulted in satisfactory results as presented in Fig. 5, Fig. $6(\mathrm{a})$, and Table 2, was $3.6 \times 10^{-2} \mathrm{~cm} / \mathrm{h}$ at the $9 \mathrm{~m}$ long segment beginning at the toe of the upstream slope and $3.6 \times 10^{-3} \mathrm{~cm} / \mathrm{h}$ until the top of the dam body.

Using the measured data for the period from July 3, 2000 to May 20, 2002, the model was validated and its prediction results were compared with the measured data as shown in Fig. 7. Comparison of FEM-predicted water levels with measured water levels is shown in Fig. 8(a), with a coefficient of determination $\left(R^{2}\right)$ of 0.94 and the slope of the regression line is almost 1 and the intercept is close to 0 . This implies satisfactory predictions of the measured water levels by the developed FEM model. Fig. 8(a) also shows a bandwidth with $\mp 2 \mathrm{SE}$ (where SE is the standard error) about the regression line, where the computed SE is $0.206 \mathrm{~m}$. As seen in Fig. 8(a), there are only four points (out of 188) outside the bandwidth. In other words, bandwidth accounts for about $98 \%$ of the scatter points. This implies that the developed numerical model can predict about $98 \%$ of the measured data with $\mp 0.412 \mathrm{~m}$. The calculated RMSE and MAE values for each case as shown in Fig. 7 are given in Table 3. The average RMSE and MAE values were 0.205 and $0.165 \mathrm{~m}$, respectively. When the simulated water level data was compared to the data obtained from other piezometers, the model performance was not satisfacory in the case of P148 (Fig. 7). The related RMSE and MAE values for this piezometer were 0.27 (32\% more than the average error) and 0.25 ( $52 \%$ more than the average error), respectively (Table 3 ). This may be because this piezometer was placed in the upper alluvial deposit layer where there might exist possible cracks causing variations in the pore-water pressure (Fig. 2 ). The model was not able to consider such possible cracks and hence it underestimated the water levels in this piezometer. 

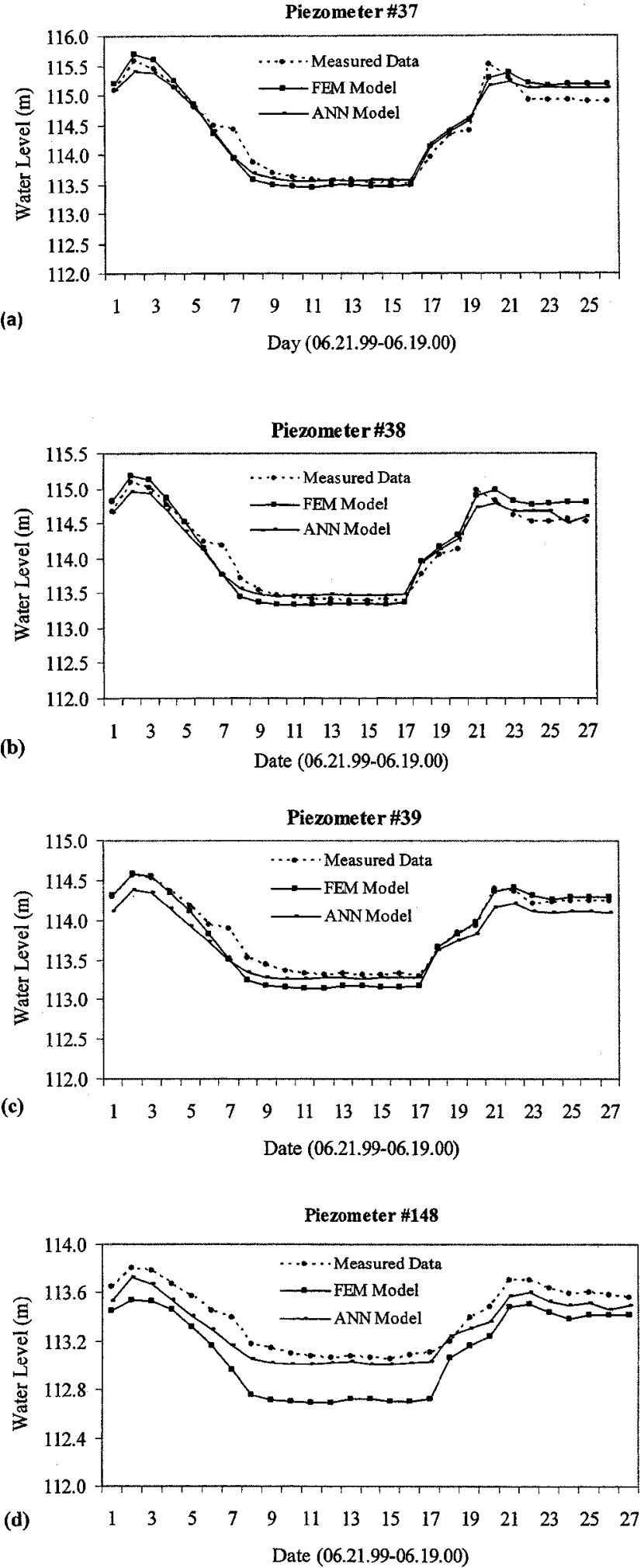

Fig. 5. Calculated and measured water levels at piezometers (a) P37, (b) P38, (c) P39, and (d) P148 for the period June 21, 1999-June 19, 2000. Calibration run

\section{Artificial Neural Network Model Training and Testing}

The ANN model had three layers-input, hidden, and output. The input layer had three neurons, the hidden layer had five neurons, and the output layer had one neuron. The input variables were upper water level, lower water level, and identification of a
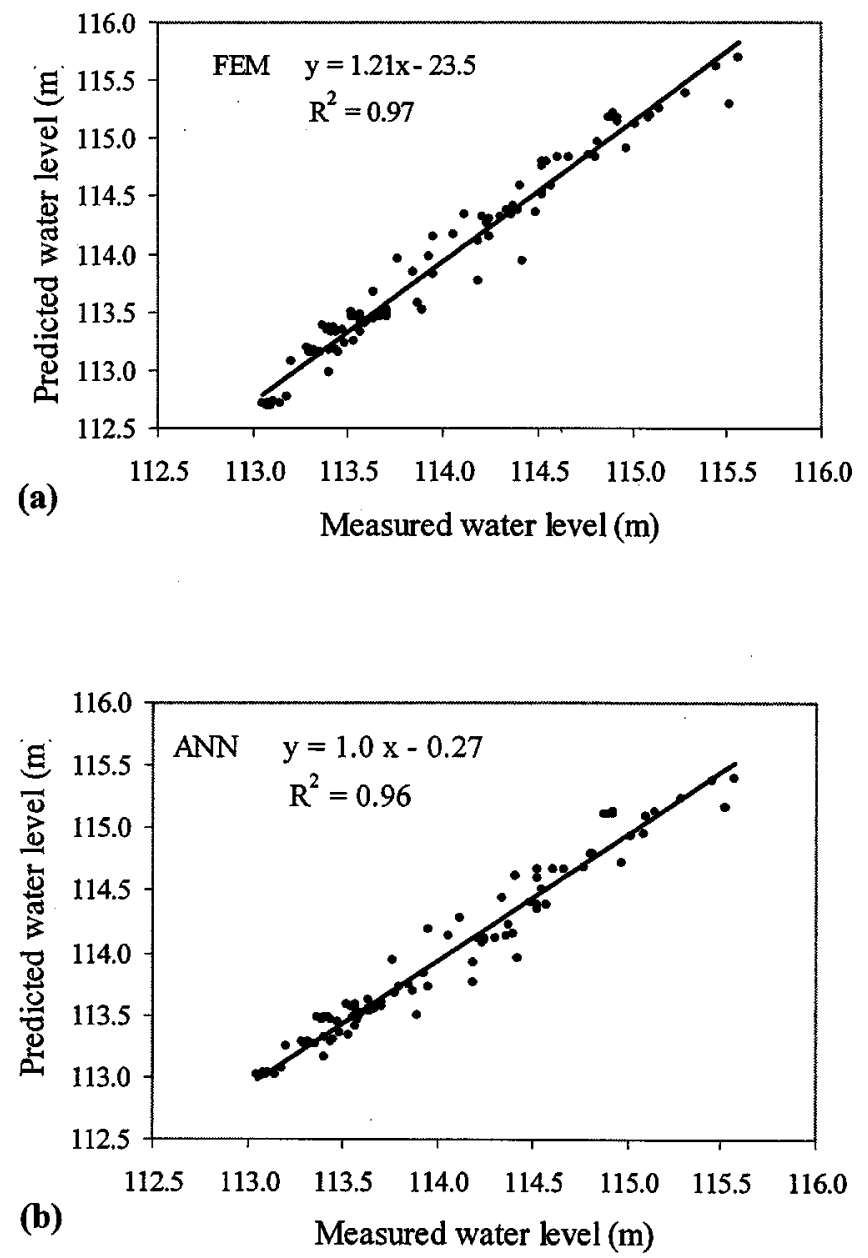

Fig. 6. Measured water levels versus predicted water levels at the calibration stage: (a) finite element method model and (b) artificial neural network model

piezometer. The numbers $70,80,90$, and 100 were used to denote the piezometers P37, P38, P39, and P148, respectively. The optimal number of neurons in the hidden layer was found by trial and error. The output variable is the water level in a piezometer. All the input and output data were compressed to the range 0.1-0.9 by Eq. (20). Small random values of $0.02-0.9$ and -1 were assigned to the network weights and biases, respectively.

The measured water level data from four piezometers used for the FEM model calibration were employed for training the network. The ANN training was carried out with a 0.01 learning rate,

Table 2. Calculated Error Measures-Calibration Run

\begin{tabular}{lccccc}
\hline & \multicolumn{2}{c}{ FEM model } & & \multicolumn{2}{c}{ ANN model } \\
\cline { 2 - 3 } \cline { 5 - 6 } Piezometer & $\begin{array}{c}\text { RMSE } \\
(\mathrm{m})\end{array}$ & $\begin{array}{c}\text { MAE } \\
(\mathrm{m})\end{array}$ & & $\begin{array}{c}\text { RMSE } \\
(\mathrm{m})\end{array}$ & $\begin{array}{c}\text { MAE } \\
(\mathrm{m})\end{array}$ \\
\hline P37 & 0.20 & 0.17 & & 0.18 & 0.13 \\
P38 & 0.17 & 0.14 & & 0.13 & 0.10 \\
P39 & 0.14 & 0.11 & & 0.16 & 0.13 \\
P148 & 0.30 & 0.29 & & 0.11 & 0.10 \\
Average & 0.203 & 0.178 & & 0.144 & 0.117 \\
\hline
\end{tabular}

Note: $A N N=$ artificial neural network; $F E M=$ finite element method $\mathrm{MAE}=$ the mean absolute error; $\mathrm{RMSE}=$ root mean square error. 

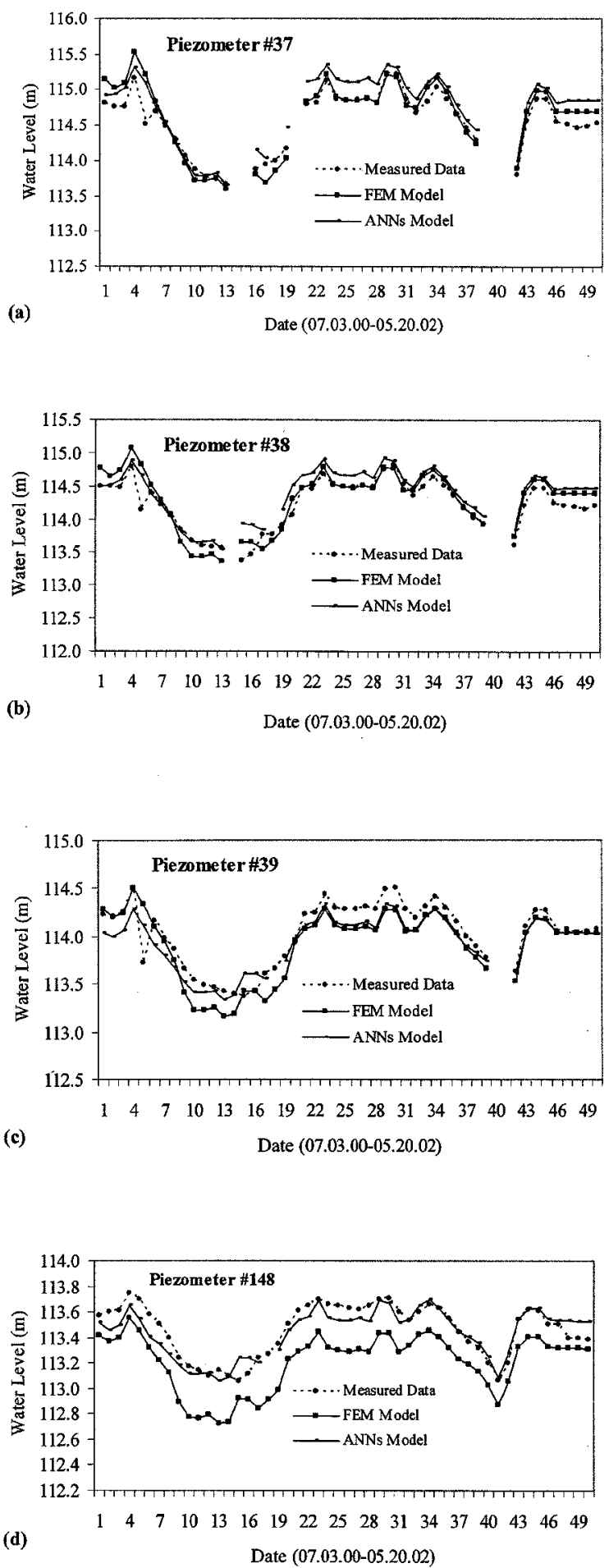

Fig. 7. Calculated and measured water levels at piezometers (a) P37, (b) P38, (c) P39, and (d) P148 for the period July 3, 2000-May 20, 2002. Validation run

a 0.04 momentum factor, and 10,000 iterations. The training runs comparing the predicted model results with the measured water level values of each piezometer are presented in Fig. 5. Fig. 6(b) shows measured water levels versus ANN-predicted water levels. The coefficient of determination $\left(R^{2}\right)$ is 0.96 and the slope of the regression line is 1 and the intercept is almost 0 . The RMSE and MAE values were computed for each case as shown in Fig. 5 and
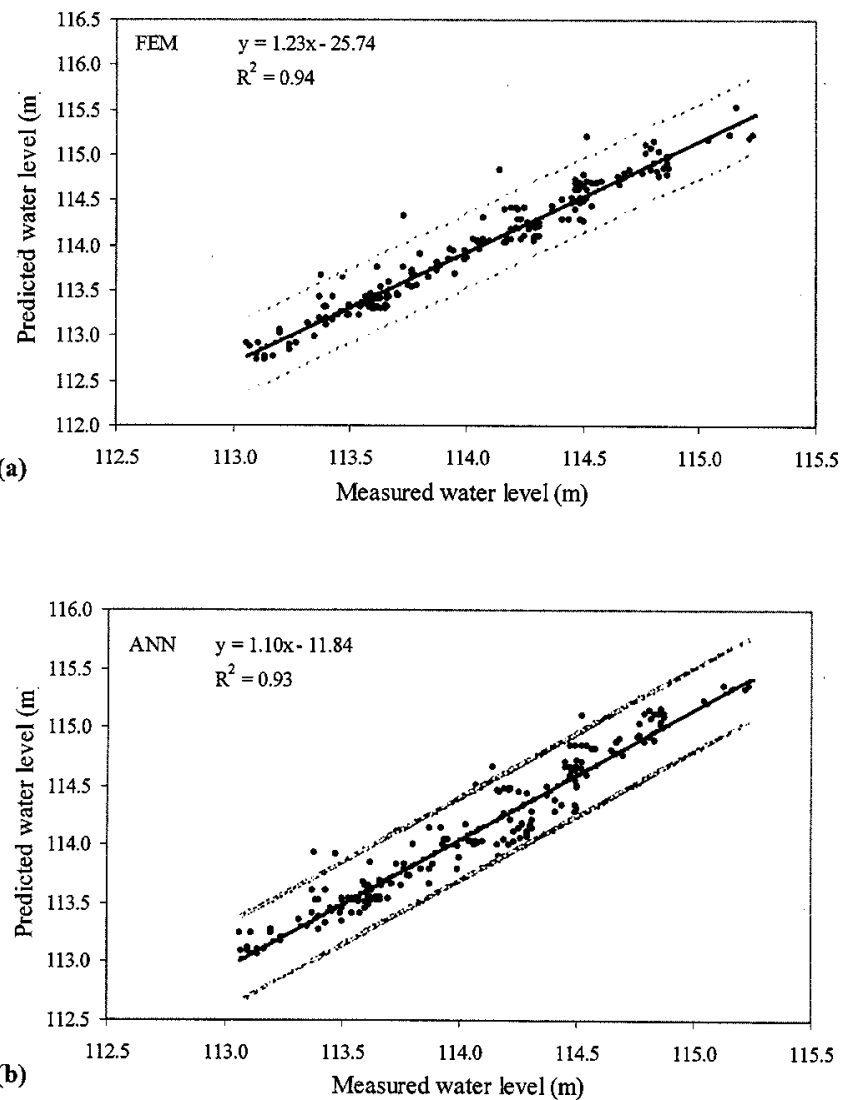

Fig. 8. (a) Measured water levels versus model predicted water levels at the validation stage: (a) finite element method model and (b) artificial neural networkmodel

summarized in Table 2. The results in Table 2, Fig. 5, and Fig. 6(b) indicate successful training of the ANN model.

The trained ANN model was then tested by predicting the measured water level data in the piezometers for the period from July 3, 2000 to May 20, 2002. The model-predicted water level for each piezometer is given in Fig. 7 from which it is seen that the ANN model satisfactorily predicted the measured water level in each piezometer. Fig. 8(b) compares the ANN-predicted water levels with the measured water levels, with a coefficient of determination $\left(R^{2}\right)$ of 0.93 and the slope of the regression line is almost 1 and the intercept is close to 0 . This indicates satisfactory predictions of the measured water levels by the developed ANN model. Fig. 8(b) also shows a bandwidth with $\mp 2 \mathrm{SE}$ about the regression line, where the computed SE value for Fig. 8(b) is

Table 3. Calculated Error Measures-Validation Run

\begin{tabular}{lccccc}
\hline & \multicolumn{2}{c}{ FEM model } & & \multicolumn{2}{c}{ ANN model } \\
\cline { 2 - 3 } Piezometer & $\begin{array}{c}\text { RMSE } \\
(\mathrm{m})\end{array}$ & $\begin{array}{c}\text { MAE } \\
(\mathrm{m})\end{array}$ & & $\begin{array}{c}\text { RMSE } \\
(\mathrm{m})\end{array}$ & $\begin{array}{c}\text { MAE } \\
(\mathrm{m})\end{array}$ \\
\hline P37 & 0.19 & 0.14 & & 0.23 & 0.20 \\
P38 & 0.18 & 0.13 & & 0.22 & 0.17 \\
P39 & 0.18 & 0.14 & & 0.15 & 0.13 \\
P148 & 0.27 & 0.25 & & 0.09 & 0.07 \\
Average & 0.205 & 0.165 & & 0.173 & 0.143
\end{tabular}

Note: $A N N=$ artificial neural network; $F E M=$ finite element method; $\mathrm{MAE}=$ the mean absolute error; RMSE $=$ root mean square error. 
$0.177 \mathrm{~m}$. It is seen that the bandwidth accounts for about $97 \%$ of the scatter points. In other words, the developed ANN model can predict about $97 \%$ of the measured data with $\mp 0.354 \mathrm{~m}$. The calculated RMSE and MAE values for each case as shown in Fig. 7 are given in Table 3. The average RMSE and MAE values were 0.173 and $0.143 \mathrm{~m}$, respectively.

\section{Comparison of Artificial Neural Network and Finite Element Method Models and Discussion}

When the ANN model is compared with the FEM model as in Fig. 7, Fig. 8, and in Table 3 it is seen that the ANN model is as good as the FEM model, especially for piezometers P37, P38, and P39. In the case of predicting the water level in P148, the ANN model performed better than the FEM model as seen from Fig. 7. In this case, the error was $0.07 \mathrm{~m}$ for the ANN model as opposed to $0.25 \mathrm{~m}$ for the FEM model (Table 3).

The physics-based model of FEM represents our best understanding of the physical process. In this model, the relations among the input and output variables are well-defined. Therefore it has universal applicability. Using this model, it is possible to obtain spatial and temporal variations of the state variables over the domain of interest under different values of the model parameters. Such information might be essential, especially for investigating any undesired cases that might happen and be detrimental to dam safety. On the other hand, the FEM model can be more effective when extensive data in the domain of interest is available. However, in practical situations satisfying all the data needs of a comprehensive FEM is seldom available due to time and budgetary constraints. For example, in this case study, no data was available on the spatial distribution of hydraulic parameters of the geological formation and the drainage outflow. The availability of such data could have improved the performance of the FEM model. Furthermore, the performance of the FEM model in predicting the water level in P148 was not satisfactory. This is because the model was not able to consider possible cracks in the alluvial deposit layer where the piezometer is placed. Furthermore, there is always a problem of convergence and instability in the numerical solution of the highly nonlinear differential equations of the physics-based model.

The ANN is a much simpler model, which has an ability to recognize the pattern between input and output variables when provided with sufficient measured field data. For example, as shown in this study, it was able to capture the pattern between the water levels in the upper and lower reservoirs and the water levels in the piezometers, thus successfully predicting the locus of the seepage path in the body of the dam in a simple and easy manner. From a practical point of view, the use of ANN in such a situation might be vital to detect any anomalies in the course of seepage and hence to develop immediate remedial measures. It should be, however, noted that ANN is a data-driven black box model which does not reveal any explicit relation between input and output variables, thus it does not provide much insight into understanding the physical problem. Furthermore, although ANN has very successful interpolation capability, it lacks the extrapolation ability for the cases for which it is not trained.

\section{Conclusions}

FEM and ANN models were developed to predict seepage through the body of an earthfill dam. In order to investigate the performances of the models, in this case study, both developed models were applied to predict temporal and spatial variation of flow through the Jeziorsko earthfill dam in Poland. Both the models were calibrated and verified using the measured data from the piezometers placed on a section of the Jeziorsko dam for monitoring seepage. The satisfactory prediction in time and space of the seepage path through the dam by the models indicate that these models can be employed to verify the piezometer readings to detect the anomalies in the course of infiltrated water and seepage and hence enable planning and implementing technically and economically sound remedial stability measures.

The following conclusions are drawn from this case study. (1) Both the FEM and ANN models exhibit comparable predictive capability, although in some piezometers ANN outperforms FEM. (2) The FEM model yields spatial and temporal variations of state variables, such as water level, whereas the ANN model yields only temporal variations of such variables. Therefore the seepage path can be easily traced. (3) The FEM model provides information on situations that may be detrimental to dam safety. (4) The FEM model uses the spatial distribution of hydraulic parameters of the geologic formation and drainage outflow, which is usually not available. The lack of such data reduces the accuracy of FEM. (5) The ANN model can estimate the locus of seepage path in a dam body. It can also detect any anomalies during the course of seepage which may need fixing. (6) ANN is more user-friendly and easier to construct than is FEM. (7) ANN predicts seepage by using only the water levels in the upper and lower pools of the dam thus requiring less and easily measurable field data. On the other hand, the FEM model requires a complicated numerical technique for the solution of the model equations, specification of the initial and boundary conditions, and values of many model parameters some of which cannot be easily measured. (8) FEM has a universal applicability while ANN is a site-specific model that requires sufficiently long historical data.

This case study might give an insight to the engineers, who are responsible for dam safety due to anomalous seepage, regarding the appropriateness of using a nondeterministic model of ANN versus a deterministic model of FEM for predicting flow through an earthfill dam under different situations.

\section{Notation}

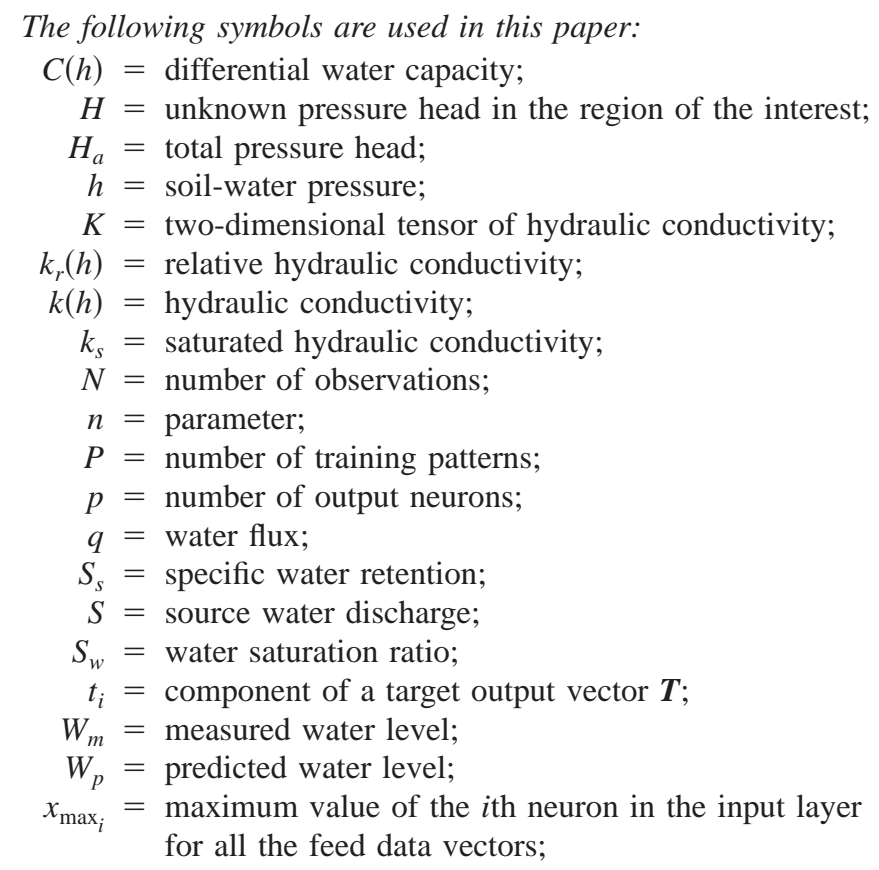




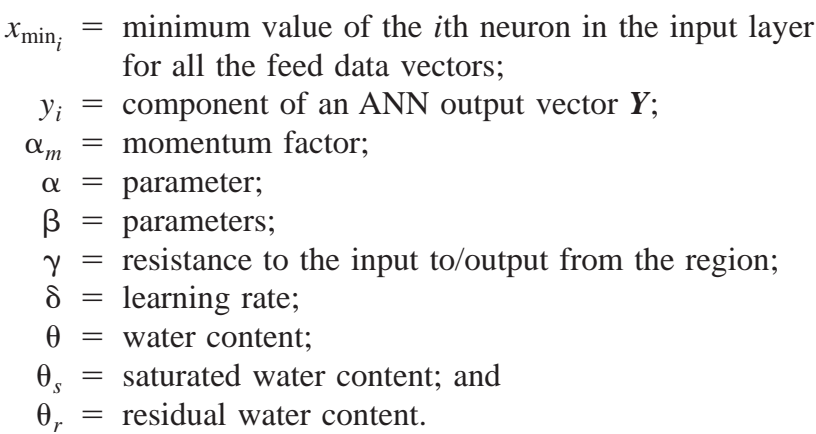

\section{References}

Abriola, L. M., and Rathfelder, K. (1993). "Mass balance errors in modeling two-phase immiscible flows: Causes and remedies." Adv. Water Resour., 16, 223-239.

ASCE Task Committee. (2000). "Artificial neural networks in hydrology, II: Hydrologic applications.” J. Hydrologic Eng., 5(2), 124-137.

Aziz, A. R. A., and Wong, K. F. V. (1992). "Neural network approach to the determination of aquifer parameters." Ground Water, 30(2), 164166.

Belmans, C., Wesseling, J. G., and Feddes, R. A. (1983). "Simulation model of the water balance of a cropped soil: SWATRE." J. Hydrol., 63, 271-286.

Burdine, N. T. (1953). "Relative permeability calculations from pore size distribution data." Pet. Trans., AIME, 198, 71-78.

Celia, M. A., Bouloutas, E. T., and Zarba, R. L. (1990). "A general mass-conservative numerical solution for the unsaturated flow equation." Water Resour. Res., 26(7), 1483-1496.

Cooley, R. L. (1983). "Some new procedures for numerical solution of variably saturated flow problems." Water Resour. Res., 19(5), 12711285.

Dawson, W. C., and Wilby, R. (1998). "An artificial neural network approach to rainfall-runoff modeling." Hydrol. Sci. J., 43(1), 47-66.

de Marsily, G. (1986). Quantitative hydrogeology, Academic, New York.

Fipps, G., and Skaggs, R. W. (1986). "Drains as a boundary condition in finite elements." Water Resour. Res., 22(11), 1613-1621.

Honjo, Y., Giao, P. H., and Naushahi, P. A. (1995). "Seepage analysis of Tarbela dam (Pakistan) using finite element method." Int. J. Rock Mech. Min. Sci. Geomech. Abstr., 32(3), 131A.

Jain, S. K. (2001). "Development of integrated sediment rating curves using ANNs." J. Hydraul. Eng., 127(1), 30-37.

Li, C. W. (1993). "A simplified Newton iteration method with linear finite elements for transient unsaturated flow." Water Resour. Res., 29, 965 971.

Lu, R.-S., Lai, J.-L., and Lo, S.-L. (1998). "Predicting solute transfer to surface runoff using neural networks." Water Sci. Technol., 38(10),
173-180.

Mualem, Y. (1976). "A new model for predicting the hydraulic conductivity of unsaturated porous media." Water Resour. Res., 12, 513-522.

Nagy, H. M., Watanabe, K., and Hirano, M. (2002). "Prediction of sediment load concentration in rivers using artificial neural network model." J. Hydraul. Eng., 128(6), 588-595.

Naouss, A. W., and Najjar, Y. M. (1996). "Seepage design charts for flat bottom dams resting on heterogeous media." Int. J. Rock Mech. Min. Sci. Geomech. Abstr., 33(3), 136A.

Neuman, S. P. (1975). "Galerkin method of analyzing nonsteady flow in saturated-unsaturated porous media." Finite elements in fluids, Wiley, New York, Vol. 1.

Paniconi, C., Aldama, A., and Wood, E. F. (1991). "Numerical evolution of iterative and noniterative methods for the solution of nonlinear Richards equation." Water Resour. Res., 27(6), 1147-1163.

Panthulu, T. V., Krishnaiah, C., and Shirke, J. M. (2001). "Detection of seepage paths in earth dams using self-potential and electrical resistivity methods." Eng. Geol. (Amsterdam), 59(3-4), 281-295.

Rajurkar, M. P., Kothyari, U. C., and Chaube, U. C. (2002). "Artifical neural networks for daily rainfall-runoff modeling." Hydrol. Sci. J., 47(6), 865-878.

Rathfelder, K., and Abriola, L. M. (1994). "Mass conservative numerical solutions of the head-based Richards equation." Water Resour. Res., 30(9), 2579-2586.

Ross, P. J. (1990). "Efficient numerical methods for infiltration using Richards' equation.” Water Resour. Res., 26, 279-290.

Swiatek, D. (2002). "Application of filtration numerical model for estimation of river embankments antiseepage protections efficiency." IMGW Research Papers, No. 13-Series: Water Engineering, Warsaw.

Tayfur, G. (2002). "Artificial neural networks for sheet sediment transport." Hydrol. Sci. J., 47(6), 879-892.

Tien-Kuen, H. (1996). "Stability analysis of an earth dam under steady state seepage." Comput. Struct., 58(6), 1075-1082.

Tocci, M. D., Kelley, C. T., and Miller, C. T. (1997). "Accurate and economical solution of the pressure head form of Richards' equation by the method of lines." Adv. Water Resour., 20, 1-14.

Tokar, A. S., and Johnson, P. A. (1999). "Rainfall-runoff modeling using artificial neural networks." J. Hydrologic Eng., 4(3), 232-239.

Turkmen, S., Ozguler, E., Taga, H., and Karaogullarindan, T. (2002). "Seepage problems in the karstic limestone foundation of the Kalecik Dam (south Turkey)." Eng. Geol. (Amsterdam), 63(3-4), 247-257.

Van Genuchten, R. (1979). "Calculating the unsaturated hydraulic conductivity with a new closed form analytical model." Research Rep., 1978-WR-08, Water Research Program Department of Civil Engineering, Princeton Univ.

Xu, Y.-Q., Unami, K., and Kawachi, T. (2003). "Optimal hydraulic design of earth dam cross section using saturated-unsaturated seepage flow model." Adv. Water Resour., 26(1), 1-7. 